\title{
Acute Behaviour of Physiological Variables in MMA Fighters Pre, During and After Competition
}

\author{
Rodrigo Poderoso de Souza*, Pedro Zorzela Poderoso, Ana Carolina Gleden Poderoso, Fabio \\ Oliveira Santos and Jefferson Campos Lopes
}

Assis Gurgazs University Center, Lupe Picasso Educational Institute, Don Bosco

*Corresponding author: Rodrigo Poderoso de Souza, Assis Gurgazs University Center, Lupe Picasso Educational Institute, Don Bosco.

To Cite This Article: Rodrigo Poderoso de Souza, Pedro Zorzela Poderoso, Ana Carolina Gleden Poderoso, Fabio Oliveira Santos, Jefferson Campos Lopes. Acute Behaviour of Physiological Variables in MMA Fighters Pre, During and After Competition. Am J Biomed Sci \& Res. 2021 13(6). AJBSR.MS.ID.001926. DOI: 10.34297/AJBSR.2021.13.001926.

Received: 眥 July 23, 2021; Published: 眥 August 12, 2021

Keywords: Acute behavior, Physiological variables, MMA fighters

\section{Introduction}

Mixed Martial Arts or Mixed Martial Arts, better known as MMA, is practiced as a regularly counted sport or in tournaments in which two competitors seek to defeat each other, having as main characteristic the freedom to combine a "MIX" of fighting modalities and/or martial arts such as boxing, muay thay, taekwondo, karate, jiu-jitsu, judo, sambô, Wrestling [1] as well as the use of various body parts to strike blows against your opponent, and the fight must be won by knockout [2].

It is understood with acute behaviour all responses resulting from a high intensity, strenuous task and these can be analysed differently or related to such tasks, seeking interpretations for this behaviour can determine a better sports performance since the planning/periodization of the training presents individualized parameters of organization and prescription-with these answers expected to be the most assertive as the physiological responses during a competition.

Several physiological variables can be observed, which is by means of direct in-heart rate analysis (HR) and/or direct analysisCortisol (COR), Lactate (LAC), Creatine Kinase (CK), Testosterone (TES), Glycemic Index (GLI); thus these markers have a direct relationship to the task/struggle, the inda; anthropometric profile characteristics of MMA fighters: fat percentage (\%G), Body Mass Index (BMI), waist/hip ratio (WHR); taking into account: Time
Of Practice (TP), Gender (GEN), age (ID), as the behaviour of the fighter facing the task: amount of blows taken during the fight.

In the National academic literature, many studies praise the profiles of MMA fighters, as well as some physiological markers of direct/indirect analysis, however, there is a lack of studies that aim to analyse the physiological variables of fighters in the real conditions of fight/competition, thus, to seek such references in the literature and present them to exalt in an orchestrated way according to the behaviour of the variables.

\section{The Objective}

Conduct a systemic review of studies of which present the physiological variables in MMA fighters; however, these variables are presented in the fighting conditions.

\section{Rand Systematic Vision}

Systemic vision requires a "mining" to fences of studies that present in a "repeated" way the same contents, related to supplementing information of a synthesizing character about the subject/question [3].

In the literature, few findings present contents that aim to analyse, observe not only physiological variables, but that these have been collected moments before the competitions, during the competitions (rounds) immediately the end of the competitions and after the recovery period $(24 \mathrm{~h})$. 


\section{Methodology}

To perform these, a research was carried out in the national electronic academic channel, using the descriptors: acute behavior, physiological variables, MMA fighters, where we could observe: (Figure 1)

According to what is observed there is an escarces in the literature when the descriptors are used: acute behavior, physiological variables, MMA fighters, the studies listed mostly form extensive publications in the book format ( $\mathrm{N} \mathrm{03),} \mathrm{literary}$ contributions being these theses and/or dissertations ( $\mathrm{N} \mathrm{01),}$ unpublished articles not having a reference character, studies focused on other modalities of fights and/or martial art ( $\mathrm{N} 09$ ) thus not corroborating the specific objective of this, as well as productions of which presented in their discourse some of the research descriptors were not consistent with the specific objective of this field research, therefore; there will be few information that may supplement or act to the detriment of this review because it does not contain materials from which it may be used in the research discursion. Thus, the nature of this work is to present the physiological variables of MMA fighters, in the pre, during (rounds) conditions, immediately after the end of the competition, and after competition/recovery (24h).

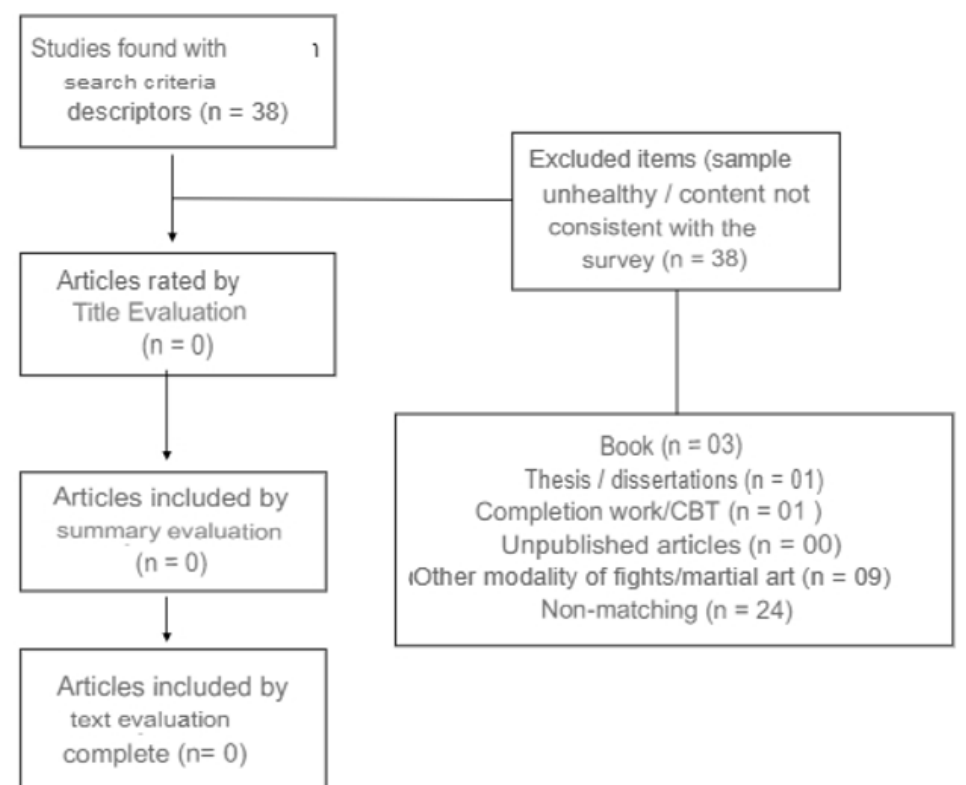

Figure 1.

\section{The Specific Objective}

Present the acute behavior of physiological variables in M.M.A fighters pre, during and after competition.

\section{Methodology}

The athletes were submitted to anthropometric evaluation (body mass, height, and percentage estimate of body fat) 24 hours before the fight and the estimated percentage of body fat measured the thickness of the skinfolds using the 3-fold method proposed by Jackson and [4]. Analysing the effect of an MMA fight on hormone levels ( $\mathrm{T}$ and $\mathrm{C}$ ) and biochemical markers, the athletes were evaluated at four distinct moments: 24 hours before $(-24 \mathrm{~h})$, one hour before $(-1 \mathrm{~h})$, immediately after $(0 \mathrm{~h})$ and 24 hours after $(+24 \mathrm{~h})$ at the end of the twenty men's fights, Professional MMA athletes, competitors in an official event, were selected according to the following inclusion criteria: he practiced the sport for at least six years; competed in at least three fights as a professional and did not use anabolic steroids or other medications that might influence the results. The subjects were divided into two groups of 10 fighters, according to the result of the fight: winners $(26.20 \pm$ 2.39 years; $86.00 \pm 16.66 \mathrm{~kg} ; 177.50 \pm 8.11 \mathrm{~cm} ; 15.62 \pm 7.21 \% \mathrm{G}$ and $9.40 \pm 2.99$ years of practice) and losers (24.30 \pm 1.83 years; $87.20 \pm 14.36 \mathrm{~kg} ; 178.90 \pm 6.94 \mathrm{~cm} ; 17.72 \pm 6.37 \% \mathrm{G}$ and $7.70 \pm$ 2.16 years of practice).

\section{Experimental Procedures}

All athletes arrived at the venue at least 48 hours before the fight and remained in a nearby hotel. The anthropometry was performed on this day on the site. Thus 24 hours before the fight, blood was collected, and this sample was collected in the accommodation. This sample, as well as the others, was performed by qualified nurses. After dandstand procedure, the athletes remained in their accommodations until two hours before the fight. At the scene one hour before the fight, a second blood sample collection was 
performed, and a third sample was performed immediately after each fight ended. Thus, the subject remained comfortably seated, with a tourniquet applied on the upper limb, when $10 \mathrm{ml}$ of blood was collected from the athlete's median cubital vein using a venous blood collection system (BD Vacutainer, New Jersey, USA). Rodrigo As reference the blood samples were transported to a certified laboratory (there is a qualiz for the laborstory) immediately after they were collected, where they were centrifugal sat at $1500 \mathrm{rpm}$ for 10 minutes (Megafuge 1.0R, Heraeus, Germany). later, the serum was removed and maintained at $-20^{\circ} \mathrm{C}$ for further laboratory analysis. Serum testosterone and cortisol concentrations were measured using radioimmunoassay kits (Cortisol Coat -RIA Count, DPC Med Lab, Los Angeles, USA) (Rosa et al., 2014). reference Biochemical variables (CK, LAC and GLU) were measured using the Integra 600 (Roche Diagnostics, Basileia, Suiça) reference equipment using the enzymatic colorimetric endpoint method (Coswig et al., 2013).

Posteriori was measured to injure waist (CINT) and hip (QUAD) measurements, rodrigo was used to measure Blood Pressure (BP) using the Missouri sphygmomanometer, with a resolution of $20.00 \mathrm{mmHg}$, so to measure heart rate (HR) using the Polar frequency meter, model F-1.

After the collection of blood material, there was a multidisciplinary team composed of nurses (12), physicians (2), while anthropometric measurements were counted on physical education professionals (11).

\section{Results}

After the evaluation of the data and variables, the same $s$ were organized in excel spreadsheet $s$ and these are presented below in the form of tables, that is, in Table 1 we will praise the measurements relevant to anthropometry (TP,\%G, BMI, CINT., QUAD., and WHR) of the athletes, already from this we will present the values of physiological markers: Table 2 cortisol (CORT.) , when in Table 3 lactate levels (LACT), iore; Table 4 possible changes in creatine kinase (CK) and finally in Table 5 numbers that match the changes in testosterone (TEST) (Table 1).

\section{Physiological Markers}

(Table 2-5)

\begin{tabular}{|c|c|c|c|c|c|c|}
\hline $\mathbf{n}$ & HO CHI MINH CITY & IMC & $\% \mathrm{G}$ & CINT & QUAD & RCQ \\
\hline 1 & 7 & 29.92 & $21.80 \%$ & 103 & 114 & 0,90 \\
\hline 2 & 12 & 28.72 & $12.60 \%$ & 86 & 101 & 0,85 \\
\hline 3 & 6 & 28.41 & $7.30 \%$ & 84 & 101 & 0,83 \\
\hline 4 & 6 & 23.88 & $8.50 \%$ & 77 & 92 & 0,84 \\
\hline 5 & 7 & 24.8 & $28.70 \%$ & 110 & 120 & 0,92 \\
\hline 6 & 15 & 33.95 & $6.90 \%$ & 75 & 90 & 0,83 \\
\hline 7 & 8 & 25.56 & $29.70 \%$ & 108 & 117 & 0,92 \\
\hline 8 & 6 & 23.1 & $9.80 \%$ & 77 & 90 & 0,86 \\
\hline 9 & 8 & 26.26 & $16.90 \%$ & 78 & 91 & 0,86 \\
\hline 10 & 7 & 26.23 & $17.20 \%$ & 75 & 91 & 0,82 \\
\hline 11 & 9 & 28.37 & $17.40 \%$ & 85 & 99 & 0,86 \\
\hline 12 & 6 & 28.68 & $22.30 \%$ & 104 & 115 & 0,90 \\
\hline 13 & 10 & 25.62 & $24.30 \%$ & 95 & 103 & 0,92 \\
\hline 14 & 6 & 26.33 & $12.60 \%$ & 79 & 95 & 0,83 \\
\hline 15 & 12 & 26.32 & $11.80 \%$ & 80 & 98 & 0,82 \\
\hline 16 & 6 & 24.03 & $22.40 \%$ & 100 & 110 & 0,91 \\
\hline 17 & 9 & 26.2 & $11.20 \%$ & 78 & 92 & 0,85 \\
\hline 18 & 8 & 26.79 & $15.50 \%$ & 86 & 100 & 0,86 \\
\hline 19 & 13 & 26.45 & $18.70 \%$ & 84 & 98 & 0,86 \\
\hline 20 & 10 & 26.45 & $17.80 \%$ & 85 & 99 & 0,86 \\
\hline
\end{tabular}

Note: $\mathrm{N}$ : identification of the athlete, TP.: time of practice in years, \%G.: fat percentage, BML.: body mass index, CINT: waist circumference in centimetres, QUAD.: hip circumference in centimetres, WHR.: waist-to-hip ratio. 
Table 2: Cortisol and/dl.

\begin{tabular}{|c|c|c|c|c|}
\hline $\mathbf{n}$ & COURT-24h & COURT-1h & COURT Oh & COURT $+24 h$ \\
\hline 1 & 0,78 & 7,18 & 22,43 & 4,78 \\
\hline 2 & 11,13 & 11,78 & 25,23 & 7,45 \\
\hline 3 & 13,78 & 16,98 & 27,55 & 11,94 \\
\hline 4 & 14,54 & 17,63 & 28,06 & 13,45 \\
\hline 5 & 14,9 & 17,64 & 28,64 & 13,78 \\
\hline 6 & 15,55 & 20,55 & 30,48 & 13,78 \\
\hline 7 & 15,79 & 20,65 & 30,97 & 13,88 \\
\hline 8 & 15,8 & 21,75 & 31,77 & 14,71 \\
\hline 9 & 16,43 & 22,13 & 31,78 & 14,72 \\
\hline 10 & 16,8 & 22,51 & 32,29 & 14,98 \\
\hline 11 & 17,37 & 23,12 & 32,4 & 15,55 \\
\hline 12 & 18,33 & 23,55 & 32,93 & 17,63 \\
\hline 13 & 19,22 & 24,55 & 32,95 & 17,72 \\
\hline 14 & 21,67 & 24,85 & 33,46 & 17,96 \\
\hline 15 & 21,67 & 25,31 & 33,85 & 18,98 \\
\hline 16 & 21,7 & 25,54 & 34,81 & 19,06 \\
\hline 17 & 21,8 & 26,67 & 34,98 & 20,3 \\
\hline 18 & 23,52 & 27,12 & 35,56 & 21,02 \\
\hline 19 & 24,54 & 28,15 & 35,58 & 21,86 \\
\hline 20 & 25,5 & 29,83 & 39,36 & 23,2 \\
\hline
\end{tabular}

Note: N.: athlete id, CORT-24h: cortisol 24h (before), CORT -1h: cortisol 1h (before), CORT Oh cortisol (immediately at tis rmino of the competition), CORT $+24 \mathrm{~h}$ cortisol $24 \mathrm{~h}$ (after $24 \mathrm{~h}$ after the end of the competition).

Table 2: Lactate $\mathrm{mmol} / \mathrm{l}$.

\begin{tabular}{|c|c|c|c|c|}
\hline $\mathbf{n}$ & LACT $-24 h$ & LACT -1h & LACT Oh & LACT $+24 h$ \\
\hline 1 & 0,6 & 1,2 & 5,6 & 0,9 \\
\hline 2 & 0,7 & 1,3 & 9,6 & 1,2 \\
\hline 3 & 0,9 & 1,3 & 11,1 & 1,3 \\
\hline 4 & 1,1 & 1,4 & 11,2 & 1,3 \\
\hline 5 & 1,2 & 1,7 & 11,2 & 1,5 \\
\hline 6 & 1,2 & 1,7 & 11,5 & 1,5 \\
\hline 7 & 1,2 & 1,9 & 12,3 & 1,5 \\
\hline 8 & 1,3 & 2,1 & 13,4 & 1,5 \\
\hline 9 & 1,4 & 2,1 & 13,8 & 1,6 \\
\hline 10 & 1,4 & 2,1 & 13,9 & 1,7 \\
\hline 11 & 1,5 & 2,4 & 14,1 & 1,7 \\
\hline 12 & 1,5 & 2,4 & 14,2 & 1,7 \\
\hline 13 & 1,5 & 2,5 & 14,4 & 1,8 \\
\hline 14 & 1,5 & 2,5 & 14,5 & 1,8 \\
\hline 15 & 1,5 & 2,6 & 14,7 & 1,9 \\
\hline 16 & 1,6 & 2,6 & 15,1 & 1,9 \\
\hline 17 & 1,7 & 2,6 & 15,2 & 1,9 \\
\hline 18 & 1,8 & 2,6 & 15,3 & 2,6 \\
\hline 19 & 1,8 & 2,7 & 15,6 & 2,7 \\
\hline 20 & 2,2 & 2,7 & 15,8 & 3,4 \\
\hline
\end{tabular}

Note: N.: athlete identification, LAC $24 \mathrm{~h}$ lactate $24 \mathrm{~h}$ (before), LAC $-1 \mathrm{~h}$ lactate $1 \mathrm{~h}$ (before), LACT -Oh lactate (immediately at the end of the competition), LAC +24h (after 24h end of the competition). 
Table 4: Creatine kinase and/l.

\begin{tabular}{|c|c|c|c|c|}
\hline $\mathbf{n}$ & $\mathbf{C K}-\mathbf{2 4 h}$ & $\mathbf{C K}-\mathbf{1 h}$ & $\mathbf{C K} \mathbf{0 h}$ & $\mathbf{C K}+\mathbf{2 4 h}$ \\
\hline 1 & 135,1 & 137,4 & 225,9 & 31,7 \\
\hline 2 & 162,1 & 137,7 & 247,8 & 57,9 \\
\hline 3 & 258,6 & 211,6 & 318,5 & 628,3 \\
\hline 4 & 261,4 & 222,1 & 322,9 & 764,1 \\
\hline 5 & 497,4 & 232,1 & 364,6 & 1150,4 \\
\hline 6 & 508,3 & 249,5 & 378,1 & 1204,2 \\
\hline 7 & 525,8 & 309,9 & 385,7 & 1220,1 \\
\hline 8 & 532,9 & 319,5 & 412,2 & 1251,2 \\
\hline 9 & 538,6 & 396,4 & 433,3 & 1345,7 \\
\hline 10 & 539,3 & 428,1 & 478,9 & 1531,9 \\
\hline 12 & 542,8 & 470,1 & 516,1 & 1545,9 \\
\hline 13 & 552,7 & 501,1 & 524,4 & 1717,7 \\
\hline 14 & 575,7 & 507,3 & 581,7 & 1865,5 \\
\hline 15 & 589,9 & 525,4 & 634,4 & 1978,9 \\
\hline 16 & 591,1 & 543,5 & 635,5 & 2365,5 \\
\hline 17 & 597,9 & 598,9 & 685,3 & 2448,4 \\
\hline 19 & 648,5 & 606,3 & 707,4 & 2496,8 \\
\hline
\end{tabular}

Note: N.: athlete identification, CK-24h creatine kinase $24 \mathrm{~h}$ (before), CK -1 creatine kinase $1 \mathrm{~h}$ (before), CK 0h creatine kinase (immediately at the end of the competition), $\mathrm{CK}+24 \mathrm{~h}$ creatine kinase $24 \mathrm{~h}$ (after $24 \mathrm{~h}$ end of competition).

\begin{tabular}{|c|c|c|c|c|}
\hline $\mathbf{n}$ & TEST $-24 h$ & TEST $-1 \mathrm{~h}$ & TEST $0 \mathrm{~h}$ & TEST $+24 \mathrm{~h}$ \\
\hline 1 & 286,4 & 143,7 & 102,8 & 194,6 \\
\hline 2 & 435,8 & 168,6 & 120,2 & 240,4 \\
\hline 3 & 438,4 & 228,3 & 145,5 & 272,7 \\
\hline 4 & 442,2 & 250,6 & 146,3 & 320,8 \\
\hline 5 & 462,9 & 258,3 & 183,9 & 325,9 \\
\hline 6 & 487,5 & 305,9 & 218,8 & 356,4 \\
\hline 7 & 491,6 & 323,1 & 249,1 & 358,4 \\
\hline 8 & 495,1 & 398,5 & 271,8 & 375,8 \\
\hline 9 & 505,5 & 414,7 & 275,1 & 395,4 \\
\hline 10 & 507,5 & 420,5 & 289,5 & 425,4 \\
\hline 11 & 518,5 & 426,3 & 300,8 & 448,1 \\
\hline 12 & 522,9 & 431,3 & 302,5 & 464,6 \\
\hline 13 & 523,9 & 435,8 & 305,5 & 498,8 \\
\hline 14 & 528,8 & 436,5 & 325,7 & 498,9 \\
\hline 15 & 540,7 & 437,3 & 343,1 & 505,5 \\
\hline 16 & 618,3 & 463,2 & 343,8 & 510,6 \\
\hline 17 & 627,5 & 472,1 & 354,5 & 537,1 \\
\hline 18 & 640,9 & 478,5 & 355,4 & 577,7 \\
\hline 19 & 644,6 & 494,4 & 405,9 & 578,5 \\
\hline 20 & 645,9 & 524,6 & 451,2 & 590,5 \\
\hline
\end{tabular}

Note: $\mathrm{N}$.: athlete id, TEST-24h testosterone24h (before), TEST $-1 \mathrm{~h}$ testosterone $1 \mathrm{~h}$ (before), TEST $0 \mathrm{~h}$ testosterone (immediately at the end of the competition), TEST $+24 \mathrm{~h}$ testosterone $24 \mathrm{~h}$ (after). 


\section{Discussion}

Table 1 shows anthropometric relationship measurements, individual information according to the athlete, so we can enhance a minimum Practice Time (TP) of 6 years and maximum 15 years; [5] observed that field tennis athletes, more experienced by the time of practice presented a greater tactical repertory when compared toyounger or less experienced athsletesin this research, the athletes involved in this research can be considered expert athletes in the modality.

Although the Body Mass Index (BMI) marker is a marker that can indicate a false-positive condition-by using the equation (weight $\mathrm{x}$ height ${ }^{2}$ )when weight in this equation refers to total weight-not "isolating" lean weight and fat weight, i.e. athletes relevant to these studies are at moderate levels of obesity-grade l, once the fat percentage values $(\% G)$, for males when the normative values of classification according to which Jackson, Wilmore, 1993 are observed; they are classified: EXCELLENT 10\% (N-2), GOOD 25\% (N-5), ABOVE AVERAGE 15\% (N-3), AVERAGE 15\% (N-3) , BELOW AVERAGE 15\% (N-3), BAD 15\% (N-3), VERY BAD 10\% (N-2); thus it was noted that, the athletes are with divergent classifications.

Authors such as [6] observed the waist circumference of jiu-jitsu fighters (N-11), whose analysis will be that $52 \%$ of the evaluated those presented acceptable measures of this marker (seek normative table).

Thus, through the WAIST/HIP RATIO (WHR), we can list 20\% $(\mathrm{N}-4)$ of the evaluated individuals presented WHR values $>0.90$, i.e., these individuals are more susceptible to metabolic diseases when only this physiological marker is observed. This statement assumes of Lean and collaborators [7] of which refer to the cut-off point 94-102cm for men characterizing risk (level 1) and increased risk (level 2) above these numbers, so we can observe that the athletes involved in these present risks, however not accentuated.

\section{Insert possible statistical analysis-Cortisol}

In adverse stress conditions, the endocrine system contributes to the increase of several glucocorticoides, cortisol(hydrocortisone, compound F) being the most important among these [8], which is considered a stress hormone [9-11], it is worth mentioning that according to the circadian cycle this can exhibit variations, thus the same has maximum peaks in the second half of the morning and declines during the day; still, minimum values in the early evening [12], this marker should be related to competitive stress, however the same in some studies has been observed as a marker of overtraining-when exposed to high levels of training and/or in chronic conditions, [13] Kim, et al. 2009 analysed behavior in golf athletes and observed that cortisol levels were higher than competitions(the analyses collected and at rest , before, during and after competitions).

\section{Insert possible statistical analysis - Lactate}

Observing lactate variations allows them to determine not only the intensity of training with the zones of metabolic transitions, commonly observed the concentration of lactate at rest varies between 0.7 and $1.0 \mathrm{mM}$ [14], and these values can vary exponentially between 20.0 and 25.0mM [15]. Authors such as [16]

suggest that the concentration close to $4.0 \mathrm{mM}$ corresponds to the anaerobic threshold, being considered maximum effort intensity with predominance of the aerobic system. [17] presents a study with 6 MMA athletes where lactate analyses were proposed at different times (rest, the end of each round/fight and after five and seven minutes at the end of the fight), where they observed a variation between which corroborate other findings involving MMA athletes however these athletes were evaluated in post-race conditions-being with predominant collaboration of other energy pathways the lactate variations observed in this study were 10.7 and $20.7 \mathrm{mM}$ [18]; thus other studies involving different modalities of fighting as boxing also corroborate the lactate variations in several rounds, but this mode of fighting has a characteristic of time that is divergent from the MMA modality. Studies suggest that lactate concentrations present such behavior due to the time of each roud's [19] being this at high intensities-characterizing a glycolytic nature of the energy pathway [20].

\section{Insert possible statistical analysis - Creatine Kinase}

Several studies praise the analysis of plasma concentrations of Creatine Kinase (CK), which is used as an indicator of stress on skeletal muscles due to activity [21-23], still; as a load monitoring marker $[24,25]$ so the more intense the activity, the greater the microcracks in the musculature-allowing greater extravasation of this enzyme into the extracellular medium.

A study conducted with jiu-jitsu fighters (N-5) observed mean creatine concentration values, however as a statistical difference between the pre $(48.1 \mathrm{mmol} / \mathrm{L})$ and post-fight $(58.7 \mathrm{mmol} / \mathrm{L})$ moments [26], thus being the normality rate between 26 and 189 $\mathrm{U} / \mathrm{L}$ - according to the Hermes Pardini Institute of Clinical Pathology (2002).

\section{Insert possible statistical analysis - Testosterone}

Testosterone, considered as the main androgen of circulation, being responsible for the development and maintenance of male and anabolic sex of tissues, is synthesized from cholesterol from the synthesis of Low-Density Lipoprotein (LDL).

\section{References}

1. Mayeda D, Ching D (2008) Fighting for Acceptance: Mixed Martial Artists and Violence in American Society. iUniverse Edição do Kindle, locais do Kindle pp. 220-222. 
2. (2019) Unified Rules and Other Important Regulations of Mixed Martial Arts. UFC.

3. Thomas Jr, Nelson J K, Silverman Sj (2012) Physical activity research methods. (6th Ed.) Porto Alegre: Artmed.

4. Pollock M L, Wilmore JH (1993) Health and disease exercises: evaluation and prescription for prevention and rehabilitation.

5. Garcia Lg, Moreno Arroyo, Moreno Domínguez A, Iglesias Gallego D, Del Villar Álvarez F (2009) Study of The Relationship Between Knowledge and Decision-Making In Tênis Players, And Their Influence On Sports Expertise. International Journal of Sport Science 17(5): 60-75.

6. Andreato L V, Franchini E, Morares SM F, João Victor Del Conti Esteves, Juliana Jacques Pastório (2012) Morphological profile of elite Brazilian Jiu-Jitsu athletes. B Rev Bras Med Esporte 18(1): 46-50.

7. Lean Mej, Han Ts, Morrison Ce (1995) Waist circumference as a measure for indicating need for weight management. BMJ. 311: 158-161.

8. Wilmore E J, Costill D (2003) Physiology of Sport and Exercise (1st ed.). São Paulo: Manole.

9. Kim KJ, Chung JW, Park S, Shin JT (2009) Psychophysiological stress response during competition between elite and non-elite Korean junior golfers. Int J Sports Med 30(7): 503-508.

10. Soares A J, And Alves MG (2006) Cortisol as a variable in health psychology. Psychology, Health and Diseases 7(2): 165-177.

11. Suay F, Salvador A, González Bono E, Sanchís C, Martínez M, et al. (1999) Effects of competition and its outcome on serum testosterone, cortisol and prolactin. Psychoneuroendocrinology 24(5): 551-566.

12. Hofstra WA, De Weerd A W (2008) How to assess circadian rhythm in humans: A review of literature. Epilepsy Behav 13(3): 438-444.

13. Houston M E (2001) Basic biochemistry of exercise science. Sao Paulo: Roca.

14. Gobatto CA, Régis E, Ayumi K (2000) Blood lactate and heart rate responses in two different motoring tests. Revista Brasileira de Medicina do Esporte 6
15. Faude 0, Kindermann W, Meyer T (2009) Lactate threshold concepts: how valid are they? Sports med 39(6): 469-490.

16. Heck H, Mader A, Hess G, Mucke S, Muller R, et al. (1985) Justification of the $4 \mathrm{mmol} / \mathrm{l}$ lactate threshold. Int J Sports Med 6(3): 117-130.

17. Siqueira Afl, Arruda A, Schwinge PA (2016) Lactate and subjective perception of effort in simulated struggle by MMA athletes. Think practice 19: 3

18. Amtmann Ja, Amtmann K A, Spath Wk (2008) Lactate and Rate of Perceived Exertion Responses of Athletes Training for And Competing in A Mma Event. J Strength Cond Res 22(2): 645-647.

19. Del Vecchio F B, Hirata Sm, Franchini E (2011) A review of time-motion analysis and combat development in mixed martial arts matches at regional level tournaments. Perceptual and motor skills 112(2): 639648.

20. Gastin P B (2001) Energy System Interaction And Relative Contribution During Maximal Exercise. Sports Med 31(10): 725-741.

21. Ispirlidis I, Fatouros IG, Jamurtas AZ, Nikolaidis MG, Michailidis I, et al. (2008) Time-course of Changes in Inflammatory and Performance Responses Following a Soccer Game. Clin J Sport Med 18(5): 423-431.

22. Yamin C, Amir O, Sagiv M, Attias E, Meckel Y, et al. (2007) ACE ID genotype affects blood Creatine Kinase response to eccentric exercise. J Appl Physiol 103(6): 2057-2061.

23. Plebani M (2010) Skeletal muscle biomarkers: not new but still interesting diagnostic tools. Clin Chem Lab Med 48(6): 745-746.

24. Brancaccio P, Maffulli N, Limongelli FM (2007) Creatine kinase monitoring in sport medicine. Br Med Bull 81-82(1): 209-230.

25. Brancaccio P, Maffulli N, Buonauro R, Francesco Mario Limongelli FM (2008) Serum Enzyme Monitoring in Sports Medicine. Clin Sports Med 27(1): $1-18$

26. Verli MVA, Afonso FP (2020) Biochemical analysis and handgrip strength in high-level Brazilian Jiu-Jitsu athletes after simulated fight. Revitsa Panoramic. 